\title{
A REVIEW ON BIO-FUELS AND ITS MANUFACTURING
}

\section{BINAYAK PATTNAYAK, SHAKTI PRAKASH JENA \& RAJARAM MOHANTY}

Institute of Technical Education and Research, Siksha 'O'Anusandhan Deemed to be University, Bhubaneswar, Odisha, India

Aim of this paper is to examine the bio-fuels and its assembling. Bio-fuel is any fluid fuel, which is preoccupied or got from bio-materials like trees, grass, crops, farming waste materials. Bio-powers can be delivered from any carbon source that can be re-established for a specific timeframe. Bio-powers are utilized all-inclusive in enterprises and in different spots. It is essential for the world to deliver this vitality in light of the fact that, there is an unfriendly impact on our condition by the use of traditional petro compound energizes. The examination reveals us in brief about bio-fuels and bio-mass, and the strategies for creation of Bio-fuels. The paper discusses the practicalities of creating the biofuels. There are a few advancements from which, we can infer bio-fuels which won't hurt nature, it the inexhaustible wellspring of vitality. Bio-fuels are extremely valuable wellspring of vitality and can be utilized in different fields. These energizes are broadly used to run the vehicle motor, as ethanol is utilized as added substance in gas to build its octane esteem, and to enhance its emanation and biodiesel is utilized in diesel. There are a few strategies made by the administration about the creation of bio-fuels on a huge scale. Government has wanted to build the generation of biofuels about 10\%-20\% continuously 2030.
\end{abstract}

KEYWORDS: Bio-Diesel, Ethanol, Bio-Mass \& Fossil Fuels

Received: Apr 17, 2019; Accepted: May 07, 2019; Published: Jun 08, 2019; Paper Id.: IJMPERDJUN2019149

\section{INTRODUCTION}

As we had talked about, bio-fuels are any fills that are gotten from as of late developing plants or small scale green growth. This wellspring of carbon can be vegetable or grain crop, or farming waste. With an expanding interest for fuel oils step by step, it is vital to search for an elective wellspring of vitality. Oil inferred fuel saves are lessening quickly because of expanding requests and it has an extremely antagonistic impact on the earth[1]. These Bio-fuels are utilized as an option in contrast to non-renewable energy sources as an increasingly reasonable and inexhaustible option for power age, and also these energizes are non-poisonous and biodegradable. Further, amid the ignition of biofuels it doesn't discharge much carbon dioxide emanation[2]. These fills have low sulphur content and have superior. A portion of the bio-fuels are ethanol, which is been gotten from the aging of starch from corn and sugarcane, bio-diesel that is acquired from vegetable and fluid creature fat, green diesel that is produced using green growth another plant sources and bio-gas that is disconnected from creature fertilizer and other processed natural material[3]. Ethanol can be utilized as a fuel for vehicles in its unadulterated structure (E100), yet it is normally utilized as a gas added substance to expand the octane estimation of the fuel and enhance vehicle emanations. Bio-diesel can be utilized as a fuel for vehicle in its unadulterated structure (B100); however it is normally utilized as diesel added substance to diminish the dimension of particulates, carbon monoxide, and, hydrocarbons, diesel motor vehicles[4]. 


\section{MANUFACTURING PROCESS}

Bio-fuels can be manufactured from biomass such as wood waste sugar and starch containing materials such as sugarcane, corn, agriculture related waste [5].

Bio-Ethanol: It is prepared from sugar cane, sugar beet, corn, algae, wood waste and agricultural residues etc.

Bio-Diesel: It is prepared from esters of fatty acid produced from vegetable oil or animal fat.

For an extensive scale generation, bio-fuels refineries are being set up so that there is a decrease of outflow of carbon mixes in the earth. The principle worry in the assembling of bio-fuels is the nourishment security as sustenance emergencies may happen as though there are plants that are developed for the generation of bio-diesel there will be less land accessible for the agrarian practices [6]. So, to maintain a strategic distance from such issue the waste land or the fruitless land can be utilized for the development of crude materials required for the generation of biofuels. In India, a few approaches are made with respect to the assembling of biofuels. The administration has chosen to set up twelve biofuels refineries, which will most likely produce $20 \%$ of bio ethanol by 2030 , with the goal that the import of raw petroleum can be diminished and the carbon mixes discharge can be decreased. Bio ethanol is added to the petroleum, as it builds its octane esteem which enhances the outflow measures of the pipe gases amid the ignition of non-renewable energy sources[7].

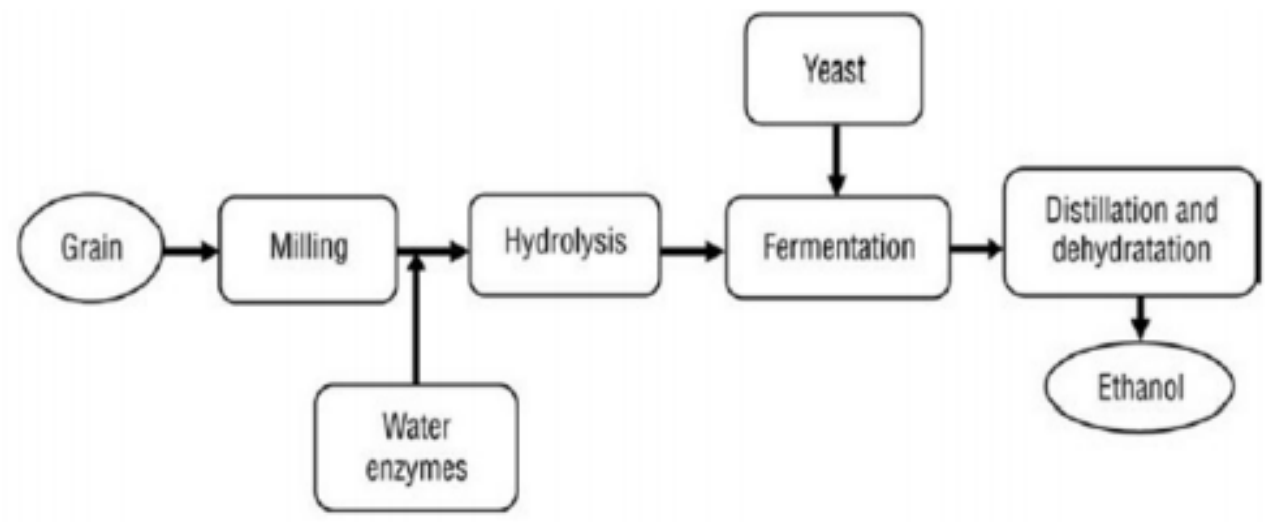

Figure 1: Ethanol Production from Grain Dry Milling (Reith et. Al, 2001)

\section{Latest Steps in the Production of Biofuels}

Liquid and gaseous fuels produced from biomass are referred to by the term biofuel. There is considerable disagreement on how to classify bio-fuels [8]. They have been normally broken into first-, second- and third-generation biofuels, nevertheless the same fuel could be categorized differently depending upon, if GHG emission stability, technology adulthood or feedstock is utilized to guide the distinction. This job employs a definition depending on the maturity of the tech and the phrases "traditional" and "advanced" for classification $[9,10]$.

\section{CONVENTIONAL AND ADVANCED BIOFUELS}

Additionally, there really certainly are a lot of systems such as power conversion convenient for software from huge and little scales. Contemplating the seminar embraced from the International Energy Agency (IEA) for its classification of biofuels," determine 2.3 provides a review of the advanced and conventional bio fuels, demonstrating processes and technologies to accessing them. It may be mentioned, with the amount of software, which particular care 
was awarded to fluid fuels [9]. Processes, which are producing biofuels, are included by Traditional technologies. All these biofuels comprise sugar- along with - starch-based ethanol centered biogas derived from digestion, in addition to biodiesel and vegetable oil. Normal feed stocks include sugar cane and sugar beet grains such as wheat and corn, oil plants such as soybean, rapeseed and petroleum jelly, as well as in a number of instances used cooking oils and animal fats. Innovative biofuel systems are transformation procedures which continue to be responsible for development, pilot or demonstration stages and research referred to as third or second creation[11]. This classification consists of hydro-treated vegetable oil (HVO), that will be derived from animal to plant and fat acrylic, in addition to bio-fuels predicated on lignocellulosic biomass, for example as cellulosic ethanol, and biomass-to-liquids (BtL) gas and Bio Synthetic gasoline (bio-SG). It has also the transformation of glucose along with bio-fuels to bio-fuels utilizing chemical or biological catalysts [9, 12]. The biofuels could be made of waste substances caused by agro forestry, agriculture, agriculture or industrial manufacturing procedures. They comprise choices also to reduce the disposition also to decrease the amount being spent on manufacturing of bio energy. The creation of cellulosic ethanol, and this is perhaps probably one of one of the absolute most promising origins of "fresh and inexpensive power", may, in theory, use as entered some raw substance comprising cellulose and hemicelluloses (for example, bypasses, straws, hulls, etc.). But, substantial progress is wanted inside this area, because these systems are not economically attainable. These procedures demand the use and also are somewhat complex. By your bio-fuels, bio diesel from cultures' creation is a more substitute type of bio-energy for a reasonable price, with all. This tech continues to be at the lab point. At the future, it is going to result in the huge scale generation of bio fuel. Even the GHG emission stability rides upon procedures and the feedstock plus it's crucial to understand that bio-fuels performance isn't consistently superior compared to that of bio fuels. Nevertheless, their evolution is propelled by ecological attention in order that they may get competitive with biofuels and also both fossil fuels. Then 1st, 2nd - and - 3rd-generation bio-fuels have been exhibited at the details [13].

\section{First Generation Biofuels}

First generation bio-fuels are the ones, which have reached a stage of business generation. Generally speaking, they are derived out of food plants. The very first production biofuels utilize agricultural feed stocks as inputs to its own production, which is true of ethanol from sugar cane and biodiesel from vegetable oils, for example instance.

\section{Sugar and Starch Based Ethanol}

From the process, sucrose is got from sugar plants such as sugar beet sugarcane and sweet sorghum, also it's then fermented by yeast to ethanol generating additional metabolic by products such as carbon dioxide. The ethanol is then recovered and concentrated by means of a range of processes. Milling: the biomass cleaned and is washed; Prep: Why water is mixed to the Sugar Cane juice and also molasses to adjust the concentration of sugar - Fermentation: yeast can be added converting sugars · Centrifugation: the solid and fluid fractions are separated; Distillation: the ethanol Found in the liquid portion is separated out of the water, using a marvel of about $95.6 \%$ (hydrated ethanol); Dehydration: how the hydrated ethanol Undergoes a process to remove the Rest of the water (azeotropic distillation, extractive distillation or molecular sieving), devising the anhydrous ethanol; - Denaturation: The ethanol to be used for gas is then denatured using a small percentage of additives, such as for example methanol, isopropanol, acetone, methyl ethyl ketone, methyl isobutyl ketone, etc., to allow it to be inappropriate to human ingestion[14]. 


\section{Second Generation Biofuels}

Instead of using quickly extractable starches, sugars, or oils in the preceding creation, instant generation biofuels do not use raw sources like raw materials. As a way to research a variety of substances they focus on feedstocks and also their parts. One example is, bio-ethanol produced from biomass. All these raw materials may be converted into bio-fuels via paths with enzymes and/or microorganisms, including microorganisms that were developed for this purpose [15]. As instant generation biofuels use different bio-conversion paths, they seemingly avoid that the "fuel versus food" dilemma. But, they can contend with the use of agricultural lands that might possibly be employed to cultivate meals crops [16]. Biomass transformation is conducted via two different normal procedures: thermochemical decomposition like gasification, bio-carbonization, liquefaction and thermal decomposition (pyrolysis) processes; and also biological nourishment, primarily referring to microbial digestion and digestion. While biological transport is ordinarily very selective and produces quite a few of different services and products in high return utilizing biological catalysts, thermal transformation often supplies multiple and intricate services and products, in rather brief intervals, along with inorganic catalysts are often used to enhance the product quality or spectrum [17].

\section{Third Generation Biofuels}

Bio-fuels of this creation include hydrogen and also algae created from biomass. This merchandise caused by this transformation has been clarified as creation only, since they do require using property. Their manufacturing technologies utilize reforming paths to transform sugars, starch and all kinds of lignocellulose into renewable substances that are concentrated. The technology for third-generation bio fuel production is at the evolution period, and also their enormous scale generation is likely from the moderate.

The "fuel into the future", has for ages been known as a fantastic supply of vitality owing to the large energy levels and sustainability and may become an integral part of the power equilibrium. Its requirement isn't confined for its own usage for a supply of vitality; the hydrogen fuel is currently useful for its creation of compounds, such as that hydrogenation of oils and fats from the foods industry to get faulty manufacturing, such as processing metal, also so for its desulfurization and also reformulation of petrol in refineries. Cons of hydrogen are the issue of storing and dispensing the hydrogen fuel, as might be necessary in widespread business applications [18]. A number of non-photosynthetic along with photo-synthetic germs, such as bacteria, cyanobacteria photosynthetic microorganisms anaerobic, along with also unicellular green algae are endowed with proteins and enzymes such as H2production their efficacy continues to be reduced [38, 48]. Other gas cells could be classified as [19]: Thermochemical gasification Pyrolysis accompanied with Reforming of fractions of all Biooil;: Immediate gratification; Novel ratification procedures; Transformation of syngas Transformation of biomass; Transformation of biomass. Hydrogen may be gotten in the biomass and fossil fuels assets. The hydrogen got from biomass as a supply of vitality, and it is called biohydrogen. Biohydrogen generation engineering continues to be at the phase of evolution and study. The optimization of bioreactor layouts and functional requirements including example light, $\mathrm{pH}$, vitamins and inflammatory structures, analysing and analysis of biological, physical and chemical pre-treatments, accelerated purification and removal of gases, immobilization of germs, along with hereditary alterations of oesophageal metabolic pathways, which take on oxygen generating receptor methods provide you exciting possibilities for bettering biohydrogen manufacturing systems [20]. Regions of search for biohydrogen Manufacturing include [21]: For attaining hydrogen Manufacturing capability · that the Re-engineering of all germs; - The Evolution of methods for optimizing and dividing the hydrogen. The plan of technologies such as biohydrogen generation accompanied 
closely by investigations along with tests. Now, gasification gives the easiest \& economic path for its creation of hydrogen. It's anticipated that steam will turn into the technology from the ending of this century [22].

\section{Future Trends of Biofuels Development}

As a way to make the most of the advantages of with them, the benefit of executing a program results taking into consideration that the features of these alternatives readily available. Your decision, which fossil fuel is much significantly suitable to restore to the transportation infrastructure's continuing near on-going future will also be vital problems. Last but most certainly, not the least assets accessibility, water and chiefly land will likely be drawn to the preparation and choice procedures. As of this phase, the gaps one of bio-fuels will have to become understood, using analytical tools like energybalance and GHG emissions thinking about living span investigation, in addition to thinking of the resource requirement, occupation creation, the access to technologies that are necessary and fossil fuels that they may change and prices [21, 23].

\section{CONCLUSIONS}

Biofuels started initially to be produced at the late 19th century; even the growth in bio fuel creation has taken place throughout the past ten years, backed by government policies that were ambitious as well as the curiosity from the production of biofuels for transportation increased again in the mid-1970s. Besides energy stability and sustainable farming issues, the reduction of $\mathrm{CO}_{2}$ emissions and street transport's blending mandate plan to promote the value of biofuels among fossil fuel options. Biofuels are a subject using measurements that include ecological sciences, ecology, economics, agronomy, plant biology, microbiology, biochemistry, chemistry, genetics, and chemical engineering, mechanical engineering, policy and law. The complete replacement of fossil fuels by biofuels is not deemed to be achievable but, nonetheless, modern day biofuels have a critical part to fulfil the very long term to support restrict the growth of GHG emissions and consequently lead the transition from their existing petroleum-based modern culture to get a more sustainable one. First generation biofuels now are commercially available, and there are crops that are not commercially grown, are not now popular for creation or which, but which could be feed-stocks for first generation fuels. The second generation is beginning to go into the industrial period and mainly lignocellulosic residue was used for creation bio fuels production. In terms of third-generation biofuels, they are at early phases of development, and fourth production is still embryonic. The financial feasibility of those methods is a goal. Commercialization requires advancing laboratory-scale processes to increase yields and productivities. Innovative biofuels have to be competitive with goods, beating the major drivers of feedstock price ranges, along with the general process of productivity and yield.

So, it very well may be reasoned that Bio Fuels are the inexhaustible wellspring of vitality and decreases the emanation of ozone harming substances. By the utilization of second era innovations, these discharges can be decreased. Bio Fuels can diminish the reliance on oil determined fuel; they are a successful way to decrease the vitality emergencies and expanding ecological contamination.

Expanded Bio Fuels request may influence the nourishment security, so to maintain a strategic distance from such emergencies legitimate standards and directions ought to be made by the administration in controlling the development of crude material for Bio Fuels, so as to stay away from sustenance related issues.

Car part is moving towards electric vehicles from the customary IC motor vehicles. So, there is a high vitality prerequisite for example of power for the cutting edge EVs. It is troublesome and tedious technique to move to electric vehicles totally on such a vast scale, so Bio Fuels are the elective wellspring of vitality to decrease such high vitality 
necessity.

\section{REFERENCES}

1. Romani et al., "Valorization of Eucalyptus nitens bark by organosolv pretreatment for the production of advanced biofuels," Ind. Crops Prod., vol. 132, pp. 327-335, Jun. 2019.

2. Tsiligiannis and C. Tsiliyannis, "Renewable energy in cement manufacturing: A quantitative assessment of energy and environmental efficiency of food residue biofuels,” Renew. Sustain. ENERGY Rev., vol. 107, pp. 568-586, Jun. 2019.

3. P. Hellier, F. Jamil, E. Zaglis-Tyraskis, A. H. Al-Muhtaseb, L. Al Haj, and N. Ladommatos, "Combustion and emissions characteristics of date pit methyl ester in a single cylinder direct injection diesel engine," FUEL, vol. 243, pp. 162-171, May 2019.

4. Ali, W. D. A., Khudair, Z. W., \& Abed, M. J. Histopathological Changes in Male Rabbits Thyroid Gland following Drenching of Nickel Chloride and the Ameliorating Effect of Ethanolic Silybum Marianum Seeds Extract.

5. F. A. Neis, F. de Costa, A. T. de Araujo Jr., J. P. Fett, and A. G. Fett-Neto, "Multiple industrial uses of non-wood pine products," Ind. Crops Prod., vol. 130, pp. 248-258, Apr. 2019.

6. J. F. Machado et al., "Antibiotic Activity Potentiation and Physicochemical Characterization of the Fixed Orbignya speciosa Almond Oil against MDR Staphylococcus aureus and Other Bacteria,” ANTIBIOTICS-BASEL, vol. 8, no. 1, Mar. 2019.

7. H. Liu, L. Ren, H. Zhuo, and S. Fu, "Water Footprint and Water Pinch Analysis in Ethanol Industrial Production for Water Management," WATER, vol. 11, no. 3, Mar. 2019.

8. Cancela, L. Perez, A. Febrero, A. Sanchez, J. L. Salgueiro, and L. Ortiz, "Exploitation of Nannochloropsis gaditana biomass for biodiesel and pellet production," Renew. ENERGY, vol. 133, pp. 725-730, Apr. 2019.

9. Pramana, H. I., Esyanti, R. R., \& Faizal, A. The Efficiency of Growth Medium Bioconversion into Banana (Musa Acuminata, AA) Plantlet Biomass in Temporary Immersion System (TIS) RITA® Bioreactor with Different Immersion Periods.

10. S. Giacobbe et al., "Butanol production from laccase-pretreated brewer's spent grain," Biotechnol. Biofuels, vol. 12, Mar. 2019.

11. M. Czechlowski, D. Marcinkowski, R. Golimowska, W. A. Berger, and W. Golimowski, "Spectroscopy approach to methanol detection in waste fat methyl esters," Spectrochim. ACTA PART A-MOLECULAR Biomol. Spectrosc., vol. 210, pp. 14-20, Mar. 2019.

12. L. Ji, F. Lei, W. Zhang, X. Song, J. Jiang, and K. Wang, "Enhancement of bioethanol production from Moso bamboo pretreated with biodiesel crude glycerol: Substrate digestibility, cellulase absorption and fermentability," Bioresour. Technol., vol. 276, pp. 300-309, Mar. 2019.

13. K. Kohli, R. Prajapati, and B. K. Sharma, "Bio-Based Chemicals from Renewable Biomass for Integrated Biorefineries," ENERGIES, vol. 12, no. 2, Jan. 2019.

14. Swaminathan, C., \& Sarangan, J. (2012). Performance and exhaust emission characteristics of a CI engine fueled with biodiesel (fish oil) with DEE as additive. biomass and bioenergy, 39, 168-174.

15. W. Meadows et al., "Discovery of novel geranylgeranyl reductases and characterization of their substrate promiscuity," Biotechnol. Biofuels, vol. 11, Dec. 2018.

16. S. Kottuparambil, R. L. Thankamony, and S. Agusti, "Euglena as a potential natural source of value-added metabolites. A review,” ALGAL Res. BIOFUELS Bioprod., vol. 37, pp. 154-159, Jan. 2019. 
17. H. Chen, T. Li, and Q. Wang, “Ten years of algal biofuel and bioproducts: gains and pains," Planta, vol. 249, no. 1, SI, pp. 195-219, Jan. 2019.

18. M. T. Miranda, F. J. Sepulveda, J. I. Arranz, I. Montero, and C. V Rojas, “Analysis of pelletizing from corn cob waste,” J. Environ. Manage., vol. 228, pp. 303-311, Dec. 2018.

19. J. Abraham et al., "Algae toxicological assessment and valorization of energetic-laden wastewater streams using Scenedesmus obliquus," J. Clean. Prod., vol. 202, pp. 838-845, Nov. 2018.

20. P. Fragkos and L. Paroussos, "Employment creation in EU related to renewables expansion," Appl. Energy, vol. 230, pp. 935-945, Nov. 2018.

21. R. S. Weber et al., "Modularized production of fuels and other value-added products from distributed, wasted, or stranded feedstocks," WILEY Interdiscip. Rev. Environ., vol. 7, no. 6, 2018.

22. R. Rendall and M. S. Reis, "Which regression method to use? Making informed decisions in "data-rich/knowledge poor\{'\} scenarios - The Predictive Analytics Comparison framework (PAC)," Chemom. Intell. Lab. Syst., vol. 181, pp. 52-63, Oct. 2018.

23. Ayoola, A. A., Anawe, P. A. L., Ojewumi, M. E., \& Amaraibi, R. J. (2016). Comparison Of The Properties Of Palm Oil And Palm Kerneloil Biodiesel In Relation To The Degree Of Unsaturation Of Their Oil Feedstocks. International Journal of Applied and Natural Sciences, 5(3), 1-8.

24. M.-C. Hsiao, S.-S. Hou, J.-Y. Kuo, and P.-H. Hsieh, "Optimized Conversion of Waste Cooking Oil to Biodiesel Using Calcium Methoxide as Catalyst under Homogenizer System Conditions," ENERGIES, vol. 11, no. 10, Oct. 2018.

25. Meng, X. Wei, Y.-H. P. J. Zhang, Z. Zhu, C. You, and Y. Ma, "Stoichiometric Conversion of Cellulosic Biomass by in Vitro Synthetic Enzymatic Biosystems for Biomanufacturing," ACS Catal., vol. 8, no. 10, pp. 9550-9559, Oct. 2018.

26. J. Rhodes, "Plastic pollution and potential solutions," Sci. Prog., vol. 101, no. 3, pp. 207-260, Sep. 2018.

27. K. Chandel, V. K. Garlapati, A. K. Singh, F. A. Fernandes Antunes, and S. S. da Silva, "The path forward for lignocellulose biorefineries: Bottlenecks, solutions, and perspective on commercialization,” Bioresour. Technol., vol. 264, pp. 370-381, Sep. 2018 . 
